Materials and Methods This descriptive observational study was carried out in a General Hospital, over a period of 24 months between January 2010 and December 2011. All patients diagnosed with $\mathrm{AMD}$ who received at least one dose of intravitreal ranibizumab were included.

Results 77 patients were included in the study, with a total of 82 eyes treated. This involved the administration of 259 injections of intravitreal ranibizumab. Each dose cost $€ 549.75$. In total, the consumption of intravitreal ranibizumab to treat the AMD during the period of study carried an expense of $€ 142,385.25$.

Considering that the unit cost of intravitreal bevacizumab is $€ 4.08$, the administration of this drug instead of ranibizumab would have cost $€ 1,056.72$.

Conclusions Ranibizumab is 135 times more expensive than bevacizumab.

In this group of patients, the use of bevacizumab would have reduced costs by approximately $€ 141,000$.

No conflict of interest.

\section{OHP-018 COST-MINIMIZATION STUDY ASSOCIATED WITH TWO STRATEGIES OF INTRAVENOUS CHEMOTHERAPY: PERIPHERALLY INSERTED CENTRAL CATHETERS VERSUS SUBCUTANEOUS CENTRAL VENOUS ACCESS PORTS}

doi:10.1136/ejhpharm-2013-000276.392

A Nianzou, J Mayer, L Bauduin, C Chapirot, I Borget, P Tilleul. Faculty of Pharmaceutical Sciences PARIS V, Pharmacoeconomics of Drugs and Medical Devices, Paris, France

Background Subcutaneous central venous access ports (CVPs) and peripherally inserted central catheters (PICCs) are two widely used devices for the administration of chemotherapy. Many studies focus on their complications but no cost study could be found in the literature.

Purpose To determine which technique allows cost minimization in the administration of chemotherapy.

Materials and Methods We constructed a Markov chain (TreeAge Software) from literature data in which probabilities were adjusted to the duration of one cycle (21 days).

Time horizon was 5 cycles. Population was oncohaematology.

Four states were identified for patients: absence of complications; mechanical complications, infectious complications and obstructive thrombotic complications.

Three consequences were isolated: the maintenance, removal or reinstallation of the catheter.

Costs were estimated from care protocols of a French University Hospital, from treatment recommendations and the French 'Common Classification of Medical Acts'.

Results Adjusted complication rate (\%): (Table)

Cost of these strategies:

PICC (with fixture) $=€ 542$

PICC (without fixture) $=€ 486$

$\mathrm{CVP}=€ 550$

The financial gain on the purchase of PICCs doesn't recoup the costs associated with maintenance and management of their complications.

Limits: the study is based on a literature review with a low number of subjects (PICCs) and foreign data (CVPs). The foreign data cannot necessarily be applied to French practise (PICC thrombosis rate in France $<$ international rate).

Moreover unlike the CVP group, the majority of PICC complications are mechanical and therefore depend on the hospital maintenance practises.

Conclusions Costs incurred by the two strategies are equivalent; however we economise on PICCs when the care protocol doesn't change the fixture every time.
Abstract OHP-018 Table 1 Adjusted complication rate (\%)

\begin{tabular}{lllll}
\hline Complications & Infectious & Mechanical & $\begin{array}{l}\text { Obstructive/ } \\
\text { thrombosis }\end{array}$ & $\begin{array}{l}\text { Absence of } \\
\text { complications }\end{array}$ \\
\hline CVP & 0.41 & 0.16 & 0.31 & 99.1 \\
PICC & 0.76 & 9.28 & 0.76 & 82.3 \\
\hline
\end{tabular}

No conflict of interest.

\section{OHP-019 DAY-1 CALL IN AN ONCOLOGY DAY UNIT: WHAT IMPROVEMENTS?}

doi:10.1136/ejhpharm-2013-000276.393

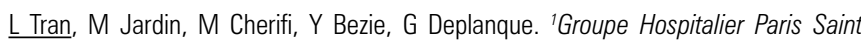
Joseph, 75014 Paris, France

Background The preparation in advance of anticancer drugs can decrease the waiting time of patients in oncology day units.

Purpose To establish a system of phoning patients before their session (D-1 call) to cheque their availability. A year after its deployment, we evaluated the impact of this plan.

Materials and Methods The oncologist and a nurse call patients one day before their appointment. The prescriptions are validated when the patient's condition permits it in the light of the patient's biological assessment, done in an outside medical analysis laboratory, and an interview using a standardised questionnaire. After pharmaceutical validation, anticancer drugs are prepared in the afternoon for the next day. Indicators of routine monitoring were defined.

Results A median of 13 patients with 23 planned day-hospital appointments were called the day before their appointment. An oncologist validated the treatment of $45 \%$ of the patients on $\mathrm{D}-1$ and $95 \%$ of the cancer treatments were delivered on D1 before 9:00 $\mathrm{am}$. The total time the patients spent in the unit was reduced from 273 minutes to 242 minutes after our plan was adopted. The average time between the end of the medical consultation and the start of the treatment went down from 79 minutes before the D-1 call to 52 minutes. In addition, $2 / 3$ of patients received the treatment only 30 minutes after seeing their doctor. Finally, fewer than $2 \%$ of anticipated preparations were not administered.

Conclusions The D- 1 call requires significant effort, but it enables us to improve the organisation of care in the oncology day unit and the preparation of the anticancer drugs by the pharmacy's production unit. The workload is more even throughout the day and is not stressful for the staff. All of this contributes to making the system safer. We are hoping to extend the D-1 call to the oncology week unit and evaluate patient satisfaction.

No conflict of interest.

\section{OHP-020 DE-ESCALATION STRATEGY OF EMPIRICAL ANTIBIOTIC TREATMENT WITH CARBAPENEMS}

doi:10.1136/ejhpharm-2013-000276.394

S Sadyrbaeva, P Aznarte Padial, N El-Fahimi, E Puerta García, S Caparrós Romero A Madrid Paredes, MA Calleja Hernández. Virgen de las Nieves University Hospital, Hospital Farmacy, Granada, Spain

Background Therapeutic de-escalation enables us to improve the effectiveness of empirical antimicrobial therapy and avoids the development of resistance.

Purpose To analyse the preliminary results of a pilot project of pharmacy interventions to achieve de-escalation of treatment with carbapenems, within a programme of optimisation of antibiotics use.

Materials and Methods Prospective study of pharmacy interventions aimed at de-escalation in patients starting treatment with carbapenems, over three months (from March to June 2012) in a 